University of Wollongong

Research Online

Faculty of Business - Papers (Archive)

Faculty of Business and Law

$1-1-2015$

Why the level-free forced-choice binary measure of brand benefit beliefs works so well

John R. Rossiter

University of Wollongong, jrossite@uow.edu.au

Sara Dolnicar

University of Wollongong, s.dolnicar@uq.edu.au

Bettina Grun

Vienna University of Economics and Business, Johannes Kepler University

Follow this and additional works at: https://ro.uow.edu.au/buspapers

Part of the Business Commons

Research Online is the open access institutional repository for the University of Wollongong. For further information contact the UOW Library: research-pubs@uow.edu.au 


\title{
Why the level-free forced-choice binary measure of brand benefit beliefs works so well
}

\begin{abstract}
The level-free version of the Forced-Choice Binary measure of brand benefit beliefs was introduced in a recent article in IJMR (Dolnicar et al. 2012) and was shown to yield more stable - hence more reliable and trustworthy - results than the shorter 'Pick-Any' measure and the longer '7-Point Scale' measure. The aims of the present article are (1) to explain how and why the Level-Free Forced-Choice Binary measure works so well, and (2) to point out its advantages over other belief measure formats - advantages that, importantly, include prevention of all forms of response bias.
\end{abstract}

\section{Keywords}

level, free, forced, choice, binary, why, measure, well, brand, benefit, beliefs, works, so

\section{Disciplines \\ Business}

\section{Publication Details}

Rossiter, J. R., Dolnicar, S. \& Grun, B. (2015). Why the level-free forced-choice binary measure of brand benefit beliefs works so well. International Journal of Market Research, 57 (2), 239-256. 


\title{
Why the level-free forced-choice binary measure of
}

\section{brand benefit beliefs works so well}

John R. Rossiter, Sara Dolnicar, and Bettina Grün

Faculty of Business, University of Wollongong

\begin{abstract}
The level-free version of the Forced-Choice Binary measure of brand benefit beliefs was introduced in a recent article in IJMR (Dolnicar, Rossiter, and Grün, 2012) and was shown to yield more stable - hence more reliable and trustworthy - results than the shorter 'Pick-Any' measure and the longer '7-Point Scale' measure. The aims of the present article are (1) to explain how and why the Level-Free Forced-Choice Binary measure works so well and (2) to point out its advantages over other belief measure formats, advantages that importantly include prevention of all forms of response bias.
\end{abstract}




\section{Why the level-free forced-choice binary measure of}

\section{brand benefit beliefs works so well}

\section{INTRODUCTION}

Beliefs about the degree to which certain products and services possess particular attributes seen as benefits represent a prevalent and important construct in marketing research. Brand benefit beliefs form the empirical basis for many commonly used marketing analyses: multidimensional scaling (e.g., Green and Rao, 1972); conjoint analysis (e.g., Green and Srinivasan, 1978); and multi-attribute attitude models, which in marketing science are called subjective expected utility models (e.g., Fishbein, 1963; Fishbein and Ajzen, 1975, 2010; McFadden, 1980). These belief-based models are used for most strategic (e.g. positioning) and operational (e.g. advertising) marketing decisions. A recent practitioner example is the pairing of tennis ace Roger Federer with Moët \& Chandon champagne, an alliance made because of the M\&C CEO's reasoning that consumers share three key beliefs about both brands: "elegance, glamor, and success" (Eggleton, 2012, p. 24). As detailed in Rossiter and Percy (1997) or Rossiter and Bellman (2005), benefit beliefs are the main construct in brand-positioning research and in commercial brand-tracking studies conducted by marketing practitioners.

When deciding how to measure brandbenefit beliefs, most academic researchers opt for a multipoint measure, most often some form of '7-Point Scale.' The well-known SERVQUAL service brand beliefs, for instance, are measured on Likert 7-point 'agreedisagree' answer scales (see Parasuraman, Zeithaml, and Berry, 1988). However, measurement of beliefs with a '7-Point Scale' is problematic, for two main reasons. One reason is that researchers use the same 7-point measure regardless of whether the attribute in 
the belief is unipolar (e.g., a laundry detergent's cleaning performance) or bipolar (e.g., evaluation of the extent to which a fast-food restaurant's offerings are healthy, on the positive side, or unhealthy, on the negative side). The SERVQUAL instrument, for example, mixes unipolar attributes (e.g., speed of response to customers) with bipolar attributes (e.g., politeness of service personnel, with strong disagreement implying that the service personnel are extremely impolite, not just lacking politeness). The main problem resulting from use of the same 7-point answer scale to measure both types of attribute is that the seven degrees of attribute intensity in a 7-point scale will tend to 'overmeasure' unipolar attributes because 'too much' discrimination is offered (see Viswanathan, Sudman, and Johnson, 2004) and at the same time will tend to 'undermeasure' bipolar attributes because 'too little' discrimination is available, with only three levels of attribute intensity on either side of the neutral midpoint.

A second serious problem is that the data obtained from 7-point and other multipoint rating measures are notoriously subject to distortion from raters' response sets (Cronbach, 1946, 1950). The most prevalent response sets are 'acquiescent' responding, 'extreme' responding, and 'midpoint' responding (Baumgartner and Steenkamp, 2001; Diamantopoulos, Reynolds, and Simintiras, 2006; Dolnicar and Grün, 2007; Tellis and Chandrasekaran, 2010; Weijters, Geuens, and Schillewaert, 2010). These response sets produce biased ratings of belief intensity; they also lead to common-measure bias in the correlations between the belief ratings measured on the same answer scale and can falsely inflate or deflate correlations depending on the type of response set adopted by the rater.

Despite these problems, multipoint belief measures continue to dominate in market research. The single exception is in practitioners' brand-tracking studies, where shorter binary measures are employed to measure brand benefit beliefs because they are much quicker for respondents to answer. The Forced-Choice Binary measure of brand benefit 
beliefs, a 2-point measure, was introduced by the British Audience Research Bureau, BARB, approximately 50 years ago (see Joyce, 1963, and also McDonald, 2000). Introduced at the same time was the Free-Choice Binary, or 'Pick-Any,' measure, which in effect is a 1-point measure. The Pick-Any measure is used today by nearly all brand- tracking companies, including the worldwide market leader, Millward Brown plc. The Pick-Any measure's popularity is due to researchers' opinion that it is more efficient to administer (it requires only a simple brand-by-attribute, rows-by-columns, matrix on the questionnaire and respondents only have to answer 'yes' to, i.e., to 'pick,' those attributes they believe the brand has, omitting all others). An earlier study by Driesener and Romaniuk (2006) compared the speed of completion of the Pick-Any measure of brands' attributes versus brands' rankings on the attributes and brands' ratings on the attributes on a 5-point Likert measure, finding that the Pick-Any measure required just half the amount of time to complete compared with the other two measures.

However, Dolnicar, Rossiter, and Grün (2012) raised three concerns about the validity of the Pick-Any measure (see also Dolnicar and Rossiter, 2008). The main concern is that 'free choosing' in Pick Any allows respondents to omit, and therefore underreport, beliefs about the brands; the proposed Level-Free Forced-Choice Binary measure is not affected by this problem because it encourages respondents to carefully consider every one of the attributes that is presented on the questionnaire. The second concern is that those attributes that are 'picked' using a Pick-Any measure are reported unstably, such that they too often fail to be picked again, even after a short time interval, and, as an apparent 'compensation,' individuals pick many new ones on the second occasion. A low two-way repeat rate of 50\%equivalent to "chance" responding by the raters - was observed in an earlier large-scale study with Pick-Any measures of beliefs (Dall'Almo Riley, Ehrenberg, Castleberry, Barwise, and Barnard, 1997); and, in Dolnicar et al.'s (2012) study, the Pick-Any repeat rate was even 
worse than chance, at $41 \%$. Underreporting and unstable responding pose great problems for brand -tracking studies in particular, because the results, when averaged over respondents, especially if they are 'rolled' as a moving average, will imply falsely that brand images are highly stable.

The final problem with all brand benefit belief measures, not just the Pick Any measure, is that the attributes frequently are worded with a fixed attribute level (e.g., 'cleans very well' for a brand of laundry detergent; or being 'extremely convenient' for a fast-food restaurant brand). The fixed level of the attribute stated in the item gets confounded with the level chosen in the answer (see Rossiter, 2002). In the laundry detergent category, for example, consumers would be logically more likely to say 'yes' if the item were worded as 'cleans well' rather than 'cleans very well.' In the fast-food restaurant category, consumers would be more likely to 'agree' if the item were worded as 'convenient' rather than 'extremely convenient.'

This last point - about levels in measures - led to the present authors' innovation in designing Forced-Choice Binary measures: the new measures are designed to be level-free in the item wording, noting that they are already level-free in the binary answer options ('yes, no' for unipolar attributes and 'agree, disagree' for bipolar attributes, with no levels between the two answer options - see examples in Appendix A). This means that the new measure is doubly level-free. Indeed, the technical name given to the new version of Forced-Choice Binary measures of beliefs (see chronologically Rossiter, 2011; Dolnicar et al., 2012; Dolnicar and Grün, 2013; and Dolnicar, in press) is DLF IIST, which stands for Doubly Level-Free Individually-Inferred Satisfaction Threshold. The second part of the name - the IIST part - refers to the information-processing mechanism through which the new version of the Forced-Choice Binary measure is theorized to work. 


\section{THE THEORY UNDERLYING THE LEVEL-FREE \\ FORCED-CHOICE BINARY MEASURE}

All multipoint brand belief measures - Likert, Semantic Differential, and so forth seek an absolute judgment. The Level-Free version of the Forced-Choice Binary measure, in a fundamental departure from this, seeks a comparative judgment (see Thurstone, 1927). The comparative judgment requires the respondent to form, or retrieve from memory, a rough estimate of the brand's believed degree of possession of the attribute, which is followed automatically by an easy determination as to whether this roughly believed degree of attribute possession meets the respondent's previously learned threshold of satisfactory attribute possession (based on the respondent's experience with brands previously encountered in the product category). Attributes, as noted above, are of two kinds: unipolar or bipolar. The upper panel of Figure 1 illustrates how unipolar attribute judgments are theorized to operate via the Level-Free Forced-Choice Binary measure, and the lower panel shows this for bipolar attributes. Note that there is one threshold for a unipolar attribute; but theoretically there are two thresholds for a bipolar attribute, one for the negative pole and another for the positive pole. However, Binary measures - like Likert measures - are always worded unipolar (see examples in Appendices A and B), which means that for a bipolar attribute either one pole must be chosen or else the two poles must be measured as separate items. Accordingly, there is only one threshold to be considered in any single brand benefit belief item.

Figure 1 about here

An alternative way of presenting the theory of how the Level-Free Forced-Choice Binary measures operate as comparative judgments is to express the process symbolically. In general, belief judgments can be denoted symbolically as $\mathrm{B}_{\text {o.a.k }}^{\mathrm{i}}$, where $\mathrm{B}=$ the belief, $\mathrm{i}=$ the individual judge or rater, $\mathrm{o}=$ the belief object (a brand of a product or a service, for instance), 
$\mathrm{a}=$ the attribute of judgment, and $\mathrm{k}=$ the level of the attribute judged to be possessed by the brand. Level-Free Forced-Choice Binary judgments are different. The belief, B, is now only a rough judgment rather than an attempted precise one, and can be denoted as $\mathrm{B}_{\text {o.a.rk, where }}^{\mathrm{i}}$ the final subscript, rk, signifies 'rough k' and allows for a range of $\mathrm{k}$ rather than a precise value. Cowley and Rossiter's (2005) range model of judgment provides the evidence that consumers do in fact have a range in mind around the attribute level even though they are asked by the researcher or by the instructions in the questionnaire to make a precise judgment by marking a single point on the rating scale. (For the earliest and sadly ignored demonstration of the 'fuzzy' nature of consumers' belief ratings, see Woodruff, 1972.) When presented with a Level-Free Forced-Choice Binary measure, such as 'Omo gets stains out:

Yes $\square$ No,' or 'McDonald's is unhealthy: $\square$ Agree $\square$ Disagree,' the supposition is that the consumer automatically brings to mind a 'standard,' or 'threshold,' that represents a learned average level of the attribute for that category of objects (laundry detergents or fastfood restaurants in the two examples). This learned average belief level can be denoted as

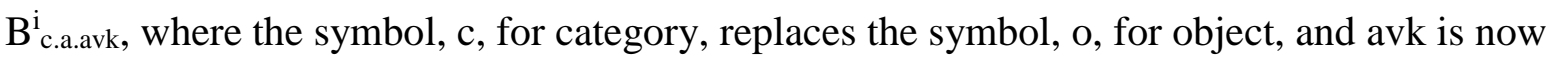
the consumer's perceived average level of the attribute for brands the consumer knows in that category. It is avk that functions as the standard for comparison. Thus:

If $\mathrm{B}_{\text {o.a.rk }}^{\mathrm{i}} \geq \mathrm{B}_{\text {c.a.avk }}^{\mathrm{i}}$, the consumer answers 'yes,' or 'agree' whereas If $\mathrm{B}_{\text {o.a.rk }}^{\mathrm{i}}<\mathrm{B}_{\text {c.a.avk }}^{\mathrm{i}}$, the consumer answers 'no,' or 'disagree' The consumer's comparative-judgment 'decision rule' is: if rk meets or exceeds avk, give an affirmative answer; but if rk is below avk, give a negative answer. The comparison is easy to make because it does not require an absolute point judgment. The comparison is so quick (see Dolnicar and Grün, 2013) that it can be presumed to be automatic. 
The theorized comparative judgment process is very different from that involved in answering on a 7-point (or other multipoint) rating scale. For instance, when making belief ratings on a 1-to-7 Unipolar Numerical rating scale, the consumer has to first make a judgment about what the anchor words at each end of the scale mean (is one end the 'zero' level of the attribute or merely the 'low' level? and is the other end the 'high' level or is it the 'extremely high' level?) and also about what the numbers mean (the number '4' in the middle of a 1-to-7 numbered scale in particular). All this decision-making takes time and, more importantly, it leads to undetectable individual variation in scale-level interpretation. Varying scale-level interpretation is considered by psychometricians to be 'random error,' or simply 'noise.'

The new Forced-Choice Binary measure substantively reduces 'noise.' This is because the between-individual variation - known as heterogeneity - is captured in the threshold term (in avk). The threshold is specific to the individual because it is based on his or her personal learning history in the product or service category. Figure 2 illustrates the consequences of this threshold. Suppose that two consumers, person A and person B, are asked to rate a brand's benefit belief on a typical '7-Point Scale' with possible scores ranging from 1 to 7 , and that both decide that the closest numerical rating that corresponds with their judgment is a 5. Does this mean that the two consumers regard the object (a brand of laundry detergent, say) as performing equally well on the attribute (cleaning performance, say)? The answer is: not at all if they have different standards - different thresholds - for what constitutes satisfactory performance. Person A's threshold is 5 in the figure, so the brand's performance would be seen by person A as satisfactory. Person B's threshold, on the other hand, is higher, namely a 6 , so person $\mathrm{B}$, despite giving the same absolute rating, would not see the brand's performance as satisfactory. The problem for multipoint rating measures, such as the one shown, is that no threshold is invoked. With the Level-Free Forced-Choice 
Binary measure the threshold is inevitably invoked because the forced-answer measure could not be answered without it. Try answering, for example, the item 'Omo gets out stains:

Yes $\square$ No' or the item 'McDonald's is convenient: $\square$ Agree $\square$ Disagree.' You will realize that neither item could be answered without having a standard or threshold for, respectively, 'stain removal' and 'convenience' implicitly in mind.

Figure 2 about here

The Level-Free Forced-Choice Binary measure's unique ability to capture heterogeneity across respondents means that, despite having only a '2-point answer scale,' it does not suffer from the 'restricted variance' problem (the problem often alleged against binary measures; see, e.g., Lehmann and Hulbert, 1972, Nunnally, 1978, and Gleason, Devlin, and Brown, 2003). Binary-answered measures are of course restricted arithmetically to 0 's and 1's, or -1 's and +1 's if bipolar, whereas the answers on a '7-Point Scale' measure can range more widely over the numbers 1 to 7 . But if much of the multipoint variation is in fact 'noise,' caused by the respondent's inability to make precise intensity judgments and by the operation of response sets, this noise will distort the true rating. With the threshold-based Level-Free Forced-Choice Binary measure, the variation is not 'noise' but is true betweenperson variation in the easy-to-make judgments of whether the brand meets or falls below the threshold for the particular attribute.

\section{MULTIPOINT MEASURES OF BELIEFS}

\section{SUFFER FROM RESPONSE BIAS}

Level-Free Forced-Choice Binary measures of brands' attributes do not require precise ratings of attribute intensity; they require only estimates of 'rough k,' rk, not 'exact 
k, $\mathrm{k}$. There is good evidence that people cannot make precise ratings of typical consumer beliefs (see Woodruff, 1972; and Cowley and Rossiter, 2005) and this indecisiveness leaves multipoint rating measures open to raters' response sets, which produce what are known as biased scores. The analysis in Table 1 summarizes how the most common multipoint measures of beliefs - Unipolar, Likert, and Semantic Differential - compare with the LevelFree Forced-Choice Binary measure for susceptibility to response sets. The major response sets are acquiescence, extreme responding, and midpoint responding, and they each lead to a particular form of bias in the ratings, as explained below.

Table 1 about here

\section{Acquiescence Bias}

Acquiescent responding, or 'yea-saying,' and its opposite, disacquiescent responding, or 'nay-saying,' occur most frequently with political or socially sensitive topics, where many people tend to give socially desirable answers. The vast majority of consumer topics - be they products, services, or in-ad presenters - are not sensitive topics. Any apparent yeasaying or nay-saying is much more likely to be halo responding caused by the respondent's favorable (positive halo) or unfavorable (negative halo) preexisting overall attitude toward the rated object. Halo responding is therefore a true response rather than an erroneous 'bias' (see Holbrook, 1983; J. Park, K. Park, and Dubinsky, 2011; and Rossiter, 2011). Acquiescent responding (as distinct from positive halo responding) can, however, show up as a response-order effect. Response-order is a more recently identified response set that occurs mainly with orally administered measures, as in face-to-face interviews or on the telephone, where the last-mentioned response option tends to be retained better in working memory and 
is thus chosen more often than it would normally be chosen on a self-administered written or online questionnaire (see Krosnick and Alwin, 1987). However, the present authors' unpublished experiments varying the order of the two answer options for Level-Free ForcedChoice Binary measures have shown no evidence of an order effect (with the online administration that was used, a first-response bias would be expected). And with orally delivered questions on the phone or in person, the two answer alternatives are easily kept simultaneously in working memory, thus precluding the response-order effect.

Practically speaking, this means that with Level-Free Forced-Choice Binary measures it makes no difference with a unipolar attribute whether you place the 'yes' answer-box first or second, and the same goes for the 'agree' answer-box with a bipolar attribute.

\section{Extreme Bias}

Extreme responding, unlike acquiescent responding, does pose a serious problem for all multipoint belief measures. Extreme responding is detectable only by examining individuals' response patterns across multiple similar items, wherein extreme responding is likely to have occurred if the respondent has 'straight-lined' down one or the other extreme side for all items. Whereas it is becoming routine for the better fieldwork companies to check for 'straight-liners,' these respondents are often retained in the data to keep up the sample size, because of the well-known rapidly worsening respondent recruitment incidence (see Menictas, Wang, and Fine, 2011). Academic researchers hardly ever report checking for such biases, so their data are almost always contaminated by extreme responding.

Extreme responding by any substantial proportion of raters will tend to artificially inflate correlations between the brand benefit belief ratings. As the findings in Table 2 reveal, the inflation will be worse for unipolar attribute measures because there is more likelihood of overdiscrimination with more answer categories with which to be 'extreme on' 
(six beyond the left-hand zero category) than with bipolar attribute measures (three on either side of the neutral midpoint). Numbering bipolar answer scales as unipolar (e.g., 1 to 7) will also inflate correlations because respondents see six categories over which to stretch their responses when in fact there are only three.

Table 2 about here

The big advantage of Forced-Choice Binary measures is that there are no extreme options: the individual has only to answer 'yes' (or 'agree') on one side of the internal threshold and 'no' (or 'disagree') on the other, and cannot answer extremely.

\section{Midpoint Bias}

Midpoint responding is another common way for respondents to 'opt out' from carefully answering survey questions (Dolnicar and Grün, in press) and, like extreme responding, it is detectable only by inspection of individuals' response patterns on multiple belief items. Midpoint responding as a 'response set' is most likely to be found with bipolar answer scales, where the midpoint is supposed to mean 'neutral' or 'neither' but is often resorted to when the respondent 'can't be bothered' answering properly (see Dolnicar and Grün, in press). Erroneous midpoint responding may occur also with unipolar answer scales when bipolar attributes are mixed in with unipolar ones. This happens frequently in Semantic Differential item batteries (see Osgood, Suci, and Tannenbaum, 1957) that mix unipolar items like 'low quality... high quality' with bipolar items like 'bad...good.'

Midpoint responding as a response bias, like extreme responding, will affect correlations between belief ratings, but in the opposing manner. Midpoint response bias will tend to deflate the correlation. With ratings entered directly to the computer these days, 
'midpoint straight-lining,' just like straight-lining on extreme answers, is easily detected but rarely corrected for by removing the offending respondents. Deflation of the correlation occurs because the between-attribute rating variance will tend toward zero if too many respondents opt out via the midpoint. It should be noted that omitting the midpoint answer option (such as using $-2-1+1+2$ answer options instead of $-2-10+1+2$ ) does not solve the midpoint opting-out problem. Respondents are likely to distribute their would-bezero opting out answers at random to one or other of the two near-midpoint categories $(-1$ or +1 in this example). Consistent near-midpoint responding will still tend to deflate the correlation between brand-image belief ratings.

Level-Free Forced-Choice Binary measures have no midpoint and thus they prevent midpoint response bias.

\section{MULTIPOINT BELIEF RATINGS ARE UNSTABLE}

An important consequence of the response biases inherent in multipoint measures of brand benefit beliefs is individual-level instability of the belief ratings, even over short periods where no actual change in the brand's attribute levels has taken place. (Note that aggregate stability - total-sample average stability as focused on in Ehrenberg's pioneering research - is not relevant, because it masks individual-level instability.) Individual-level stability can be assessed in the 'test-retest' reliability paradigm by calculating the proportion of respondents who exactly repeat their initial rating (or initial binary judgment) on a shortinterval, one- or two-week later, retest. Perfect stability (a proportion of 1.0) can be expected only among consumers who are familiar with the product category, the brand to be rated, and the attributes used in the measures (see Dolnicar et al., 2012). Some degree of stability can occur by chance and is dependent on the number of levels in the answer scale: for a 7-point answer scale, where each level is theoretically equally likely to be chosen, the chance 
stability proportion is $1 / 7 \times 1 / 7=1 / 49=.02$, and for a binary answer scale it is $1 / 2 \times 1 / 2=$ .25. Table 3 shows the exact stability proportions for 7-Point Scale ratings and Level-Free Forced-Choice Binary judgments (for the same two data sets as in the previous table). While both stability proportions are well above their respective chance proportions, the exact stability for 7-Point Scale ratings is very low, averaging about .45, compared with the exact stability for the Forced-Choice Binary measures, which in both cases is above .80 .

Table 3 about here

The 7-Point Scale measure's low exact repeatability provides empirical proof of the present authors' presumption that precise intensity ratings on multipoint answer scales are difficult to make. The Level-Free Forced-Choice Binary belief measure's judgments of whether the brand 'meets' or 'doesn't meet' the individual's established threshold for the attribute are easier to make and therefore are more stable.

\section{NO DIAGNOSTIC LIMITATION WITH LEVEL-FREE FORCED-CHOICE BINARY MEASURES}

A seeming limitation in 'switching' to Level-Free Forced-Choice Binary measures is researchers' feared loss of diagnostic capability. With multipoint belief ratings, in theory, the marketer can use multiple regression to relate the brand's benefit belief ratings to a relevant dependent variable such as Overall Attitude, Overall Satisfaction, or Purchase Intention. From the regression coefficients for the belief ratings, the market researcher can compute the 'elasticity' of each attribute and estimate the incremental gain on the dependent variable if the belief were to be increased for a positive attribute or decreased for a negative attribute. But if multipoint belief ratings are fuzzy, biased in an unknown direction, and unstable, then the 
regression weights, which are in effect partial correlation coefficients, will also be unstable. Diagnosis by regression analysis then becomes untrustworthy and, worse, misleading.

Switching to Level-Free Forced-Choice Binary measures of brand-image attributes would, at first, seem not to be the solution to the diagnostic problem because the binary judgments are seen as 'too blunt' and 'not sensitive enough' to record marketing-induced shifts in belief ratings. However, as some advertising theorists have pointed out (specifically Moran, 1985, and Rossiter and Bellman, 2005), the ultimate purpose of marketing is to get as many individual consumers as possible up to the 'go, no go' binary action threshold on the brand's targeted attribute or attributes. Unlike the Pick-Any measure, which understates the in-sample incidence of brand benefit beliefs, the Level-Free Forced-Choice Binary measure records the brand's threshold-meeting incidence for each attribute belief exactly. And unlike 7-Point or other multipoint measures, the Level-Free Forced-Choice Binary measure avoids the confound of the incidence of consumers who believe the brand has the attribute with the intensity of their belief (which is a completely neglected confound with multipoint belief ratings). For example, a service company might be rated overall 6 out of 7 for satisfying customers on an attribute such as 'response time' but this could be due to most customers being perfectly satisfied and giving the company a 7 rating while others are disaffected and give it a much lower rating. Of course, this distribution of ratings could easily be checked by inspecting individual-level responses instead of only the group-average response, but the researcher would still not know at which number to make the "cutoff" for a truly satisfactory rating. With the Level-Free Forced-Choice Binary measure there are no intensity differences in the binary answers. Consumers are merely answering either at or below their individual thresholds and this reveals pure incidence, namely: the proportion of customers who are satisfactorily satisfied with that brand's delivery of that particular attribute. 
In the hope of encouraging adoption of the Level-Free Forced-Choice Binary measure, two examples of prototype questionnaires are provided in Appendix A. The first example covers unipolar attributes for laundry detergents (scored 1,0). The second example covers bipolar attributes for fast-food restaurants (scored $+1,-1)$. A third example is shown for a modified SERVQUAL-type instrument in Appendix B, with Level-Free Forced-Choice Binary measures replacing the usual 7-point Likert answer scales used in service quality research. The attributes (service benefits) in this example are all unipolar as in Likert items, but worded level-free unlike typical Likert items, and should be scored 'yes' = 1 and 'no' = 0 to reveal individual 'at-threshold' incidence. Moreover, the brand benefit beliefs are each independent and measured single item (see Bergkvist and Rossiter, 2007) and should not be factor-analyzed or factor-scored as in SERVQUAL. Customized variations of the two product and one service questionnaires can easily be constructed from appropriate qualitative research. 


\section{APPENDIX A}

Examples of Level-Free Forced-Choice Binary measures for beliefs about unipolar attributes and beliefs about bipolar attributes (one brand shown in each case)

Laundry detergents

Omo:

$\begin{array}{lll}\text { Cleans } & \square \text { Yes } & \square \text { No } \\ \text { Removes stains } & \square \text { Yes } & \square \text { No } \\ \text { Whitens whites } & \square \text { Yes } & \square \text { No } \\ \text { Brightens colors } & \square \text { Yes } & \square \text { No } \\ \text { Freshens clothes } & \square \text { Yes } & \square \text { No }\end{array}$

Fast-food restaurants

McDonald's:

\begin{tabular}{|c|c|c|}
\hline Yummy & $\square$ Agree & $\square$ Disagree \\
\hline Quick service & $\square$ Agree & $\square$ Disagree \\
\hline Value for money & $\square$ Agree & $\square$ Disagree \\
\hline Unhealthy & $\square$ Agree & $\square$ Disagree \\
\hline Convenient & $\square$ Agree & $\square$ Disagree \\
\hline
\end{tabular}




\section{APPENDIX B}

SERVQUAL-type questionnaire modified from the Likert format to the Level-Free ForcedChoice Binary format (service category: retail banks)

Banks' previous or current customers as raters

Barclays Bank:

1. Welcoming-looking branches

$\square$ Yes

$\square$ No

2. Branch convenient to work or home

Yes

$\square \mathrm{No}$

3. Well laid-out interior facilities

Yes

$\square$ No

4. Short waiting times

Yes

$\square$ No

5. Privacy for important transactions

Yes

No

6. Polite tellers

Yes

$\square$ No

7. Competent desk personnel

$\square$ Yes

$\square$ No

8. Competitive interest rates

$\square$ Yes

$\square$ No

9. Account statements sent frequently

$\square$ Yes

$\square$ No

10. Account statements clear and accurate

Yes

$\square$ No

11. Easily usable online banking

Yes

$\square$ No 


\section{REFERENCES}

Baumgartner H, Steenkamp J-BEM. 2001. Response styles in marketing research: a crossnational investigation. Journal of Marketing Research, 38(2), 143-156.

Bergkvist L, Rossiter JR. 2007. The predictive validity of multiple-item versus single-item measures of the same constructs. Journal of Marketing Research, 44(2), 175-184.

Cowley E, Rossiter JR. 2005. Range model of judgments. Journal of Consumer Psychology, 15(3), 250-262.

Cronbach LJ. 1946. Response sets and test validity. Educational and Psychological Measurement, 6(4), 475-494.

Cronbach LJ. 1950. Further evidence on response sets and test design. Educational and Psychological Measurement, 10(1), 3-31.

Dall'Olmo Riley F, Ehrenberg ASC, Castleberry SB, Barwise TP, Barnard NR. 1997. The variability of attitudinal repeat rates. International Journal of Research in Marketing, 14(5), 437-450.

Diamantopoulos A, Reynolds NL, Simintiras AC. 2006. The impact of response styles on the stability of cross-national comparisons. Journal of Business Research, 59(August), 925-935.

Dolnicar, S. In press. Asking good survey questions. Journal of Travel Research.

Dolnicar S, Grün B. 2007. Cross-cultural differences in survey response patterns. International Marketing Review, 24(2), 127-143.

Dolnicar S, Grün B. 2013. Validly measuring destination images in survey studies. Journal of Travel Research, 52(1), 3-13.

Dolnicar, S., Grün, B. In press. Including don’t know answer options in brand image surveys improves data quality. International Journal of Market Research. 
Dolnicar S, Rossiter JR. 2008. The low stability of brand-attribute associations is partly due to market research methodology. International Journal of Research in Marketing, 25(2), 104-108.

Dolnicar S, Rossiter JR, Grün B. 2012. 'Pick any' measures contaminate brand image studies. International Journal of Market Research, 54(6), 821-834.

Driesener C, Romaniuk, J. 2006. Comparing methods of brand image measurement. International Journal of Market Research, 48(6), 681-698.

Eggleton J. 2012. The brand raquet: why Federer, Moet are a champagne union. The Australian, December 3, pp. 24, 28.

Fishbein M. 1963. An investigation of the relationships between belief about the object and attitude toward the object. Human Relations, 16(3), 233-240.

Fishbein M, Ajzen I. 1975. Belief, Attitude, Intention, and Behavior: An Introduction to Theory and Research. Addison-Wesley: Reading, MA.

Fishbein M, Ajzen I. 2010. Predicting and Changing Behavior: The Reasoned Action Approach. Psychology Press: New York.

Gleason TC, Devlin SJ, Brown M. 2003. In search of the optimum scale. Marketing Research, 15(3), 25-29.

Green PE, Rao VR. 1972. Applied Multidimensional Scaling: Comparison of Approaches and Algorithms. Holt, Rinehart and Winston: New York.

Green PE, Srinivasan V. 1978. Conjoint analysis in consumer research: issues and outlook. Journal of Consumer Research, 5(2), 103-123.

Holbrook MB. 1983. Using a structural model of halo effect to assess perceptual distortion due to affective overtones. Journal of Consumer Research, 10(2), 247-252. 
Joyce, T. 1963. Techniques of brand image measurement. New Developments in Research6th Annual Conference of the Market Research Society. London: Market Research Society, pp. 45-63.

Krosnick JA, Alwin DF. 1987. An evaluation of a cognitive theory of response order effects in survey measurement. Public Opinion Quarterly, 51(2), 201-219.

Lehmann DR, Hulbert J. 1972. Are three-point scales always good enough? Journal of Marketing Research, 9(4), 444-446.

McDonald C. 2000. Tracking advertising and monitoring brands. Admap Monograph No. 6. Henley-on-Thames, England: Admap Publications.

McFadden D. 1980. Econometric models for probabilistic choice among products. Journal of Business, 53(3), 513-530.

Menictas C, Wang P, Fine B. 2011. Assessing flat-lining response style bias in online research. Australasian Journal of Market \& Social Research, 19(2), 34-44.

Moran WT. 1985. The circuit of effects in tracking advertising profitability. Journal of Advertising Research, 25(1), 25-29.

Nunnally JC. 1978. Psychometric Theory, 2nd edn. McGraw-Hill: New York.

Olsson, U. 1979. Maximum likelihood estimation of the polychoric correlation coefficient. Psychometrika, 44(4), 443-460.

Osgood CE, Suci GJ, Tannenbaum P. 1957. The Measurement of Meaning. Urbana, IL: University of Illinois Press.

Parasuraman A, Zeithaml V, Berry LL. 1988. SERVQUAL: a multiple-item scale for measuring consumer perceptions of service quality. Journal of Retailing, 64(1), 1240.

Park JY, Park K, Dubinsky AJ. 2011. Impact of retailer image on private brand attitude: halo effect and summary construct. Australian Journal of Psychology, 63(3), 173-184. 
Rossiter JR. 2002. The C-OAR-SE procedure for scale development in marketing. International Journal of Research in Marketing, 19(4), 305-335.

Rossiter JR. 2011. Measurement for the Social Sciences: The C-OAR-SE Method and Why it Must Replace Psychometrics. Springer: New York.

Rossiter JR, Bellman S. 2005. Marketing Communications: Theory and Application. Sydney, Australia: Pearson.

Rossiter JR, Percy L. 1987. Advertising \& Promotion Management. McGraw-Hill, New York.

Rossiter JR, Percy L. 1997. Advertising Communications \& Promotion Management, 2nd edn. McGraw-Hill, New York.

Tellis GJ, Chandrasekaran D. 2010. Extent and impact of response biases in cross-national survey research. International Journal of Research in Marketing, 27(4), 321-341.

Thurstone LL. 1927. A law of comparative judgment. Psychological Review, 34(4), 273-286.

Viswanathan M, Sudman S, Johnson M. 2004. Maximum versus meaningful discrimination in scale response: implications for validity of measurement of consumer perceptions about products. Journal of Business Research, 57(February), 108-125.

Weitjers B, Geuens M, Schillewaert N. 2010. The stability of individual response styles. Psychological Methods, 15(1), 96-110.

Woodruff RB. 1972. Measurement of consumers' prior brand information. Journal of Marketing Research, 9(3), 258-263. 


\section{FIGURE 1}

HOW THE LEVEL-FREE FORCED-CHOICE BINARY MEASURE IS THEORIZED TO

OPERATE FOR UNIPOLAR ATTRIBUTES AND BIPOLAR ATTRIBUTES

\section{Unipolar performance attribute}

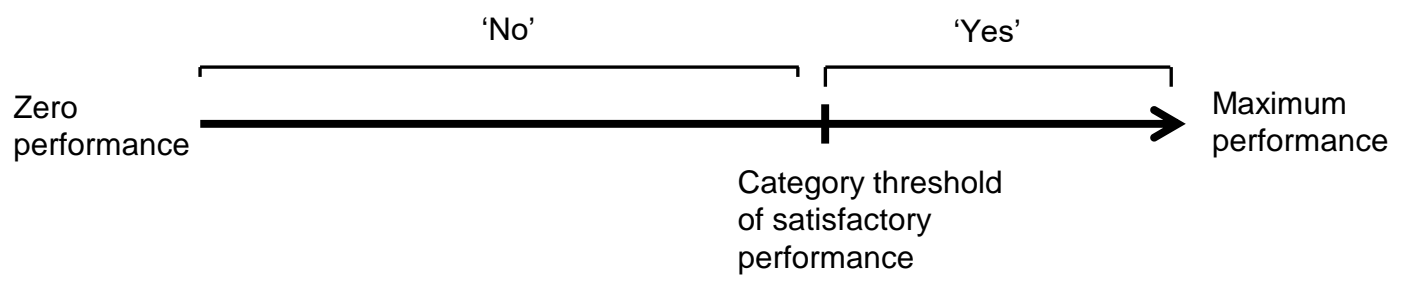

Bipolar evaluative attribute measured as two unipolar attributes
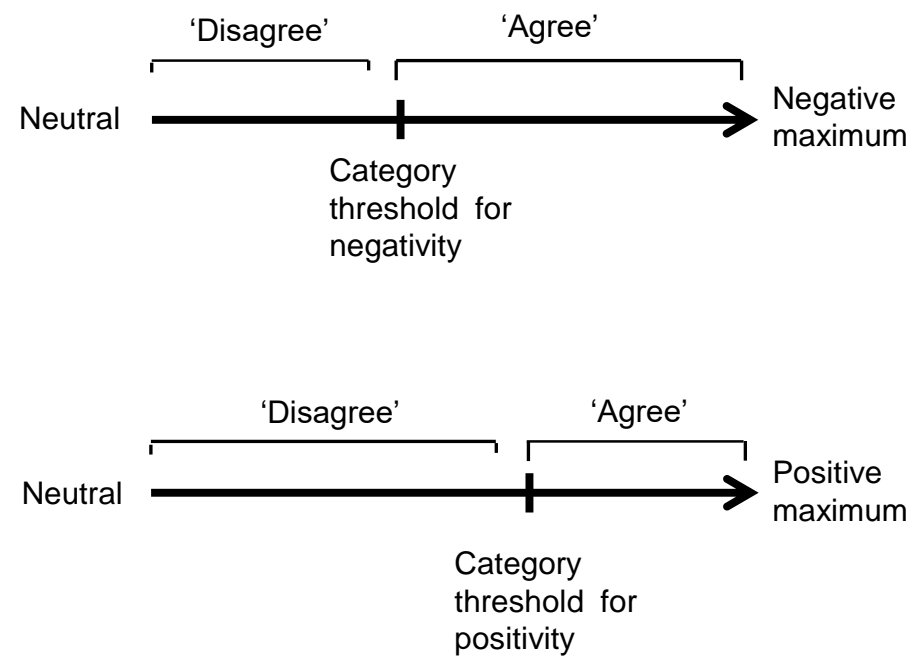


\section{FIGURE 2}

HOW THE THRESHOLD ADDS TO VALIDITY BY ACCOUNTING FOR INDIVIDUALLEVEL HETEROGENEITY

With 7-point rating measures of belief, two individuals could have identical scores of, say, $5 \ldots$

$\begin{array}{llllllll}\text { Person A } & 1 & 2 & 3 & 4 & \underline{5} & 6 & 7 \\ \text { Person B } & 1 & 2 & 3 & 4 & \underline{5} & 6 & 7\end{array}$

But if their category satisfaction thresholds for the attribute differ, this would mean a different result. If, for example:

Person A's threshold is 5 or lower, then the FC Binary answer is 'Yes.'

Person B's threshold is 6 or higher, then the FC Binary answer is 'No.' 
Table 1. Multipoint measures of beliefs are susceptible to all major forms of response set (response bias) whereas Level-Free Forced-Choice Binary measures prevent them

\begin{tabular}{|c|c|c|c|}
\hline \multirow{2}{*}{$\begin{array}{l}\text { Belief measure } \\
\text { type }\end{array}$} & \multicolumn{3}{|c|}{ Response set } \\
\hline & Acquiescence & Extremes & Midpoint \\
\hline $\begin{array}{l}\text { Unipolar } \\
\text { (not at all } \longrightarrow \text { maximum) }\end{array}$ & YES & YES & $\begin{array}{l}\frac{\text { No } \text { (unless the }}{\text { unipolar scale is }} \\
\text { wrongly } \\
\text { interpreted as } \\
\text { bipolar) }\end{array}$ \\
\hline $\begin{array}{l}\text { Likert } \\
\text { (strongly disagree } \longleftrightarrow \\
\text { strongly agree) }\end{array}$ & YES & YES & YES \\
\hline $\begin{array}{l}\text { Semantic Differential } \\
\text { (e.g., dislike } \longleftrightarrow \text { like) }\end{array}$ & YES & YES & YES \\
\hline $\begin{array}{l}\text { Level-Free FC Binary } \\
\text { (yes, no; disagree, agree) }\end{array}$ & $\begin{array}{l}\text { No (empirical } \\
\text { tests show no } \\
\text { yea-saying } \\
\text { effect) }\end{array}$ & $\begin{array}{l}\frac{\text { No }}{\text { extreme }} \\
\text { options) }\end{array}$ & $\frac{\mathrm{No}}{\text { (no midpoint) }}$ \\
\hline
\end{tabular}


Table 2. Correlations between brand-benefit belief ratings show inflation (compared with Level-Free Forced-Choice Binary judgments) when there are more scale points

$\begin{array}{ccc}\text { Level-Free } & \text { Unipolar } & \text { Unipolar } \\ \text { FC Binary } & & \\ & \text { (4-point } & \text { (7-point } \\ \text { (yes, no) } & \text { one-sided) } & \text { one-sided })\end{array}$

Correlations for laundry

.40

.74

.86

detergent brand benefit

beliefs $^{\mathrm{a}}$

Level-Free

Bipolar

Bipolar

FC Binary

(agree, disagree)

(2-point each side

(3-point each side of midpoint) of midpoint)

Correlations for fast-food .22

.26

.29

restaurant brand benefit

beliefs $^{\mathrm{b}}$

${ }^{\text {a }}$ Six brands rated on seven laundry detergent performance attributes by approximately $\mathrm{n}=$ 300 respondents per measure

${ }^{b}$ Five brands rated on five fast-food restaurant evaluative attributes by approximately $n=200$ respondents per measure 
Table 3. Absolute belief intensity ratings are "fuzzy" as indicated by the former's much lower test-retest stability when compared with Level-Free Forced-Choice Binary belief judgments

\begin{tabular}{|c|c|c|}
\hline & \multicolumn{2}{|c|}{ Exact stability proportion } \\
\hline & 7-Point & Level-Free \\
\hline & Scale & FC Binary \\
\hline Laundry detergent benefit beliefs ${ }^{\mathrm{a}}$ & .44 & .82 \\
\hline Fast-food restaurant benefit beliefs ${ }^{\mathrm{b}}$ & .46 & .85 \\
\hline Chance stability proportion & $(.02)$ & $(.25)$ \\
\hline s tabl & & \\
\hline
\end{tabular}

